\title{
Pectoralis II block beyond breast surgery
}

J. Mendes ${ }^{1}$, F. Duarte ${ }^{1}$, P. O'Neill ${ }^{1}$, M. Ghira ${ }^{1}$

1 Department of Anesthesiology of Hospital Beatriz Ângelo

\section{Background}

- Pectoralis nerve block type II (PECS II) was first described by Blanco in 2012, initially for breast surgery (1).

- Since then, wider indications are being described for PECS II (2), including minor chest wall, axillary, proximal upper extremity (3) and even small cardiac procedures (4).

- Being shoulder girdle innervation dependent on nerves not blocked by PECS II, an interscalene brachial plexus block is usually performed for such procedures and upper extremity motor block inevitably ensues.

- For ambulatory surgery, such upper extremity motor block is not desirable after patient discharge.

- We present, to our knowledge, the first case of a shoulder girdle procedure performed under PECS II and a superficial cervical plexus block.

- This allowed upper extremity motor function to be unaffected and patient discharge on the same day with no upper extremity weakness.

Case Report

- 22-year old male.

- Latarjet procedure 1 year ago.

- No more relevant past history.

- ASA PS 1.

- Now scheduled for removal of 2 glenoid bone screws as an outpatient procedure ( $X$-ray on the right).

\section{Anesthetic management:}

- $0,5 \%$ ropivacaine PECS II 0,4 mL/ $\mathrm{Kg}$ block

- Superficial cervical plexus block

- Sedation: TCI of propofol programmed at 1,5 $\mathrm{ug} / \mathrm{mL}$ (effect site concentration)

- Uneventful $2,5 \mathrm{~h}$ surgery, with absence of any intravenous intraoperative analgesia.

- Patient discharged home 1 hour after the end of surgery.

- Expectedly, no upper extremity motor block.

\section{Discussion}

- Scapular innervation in not dependent on PECS II blocked nerves, but on subscapular, suprascapular and axillary nerves.

- The PECS II and superficial plexus blocks must have provided anesthesia to the pectoral and axillary region, allowing the surgeon to have an anterior surgical approach.

- Bone screw removal anesthesia?

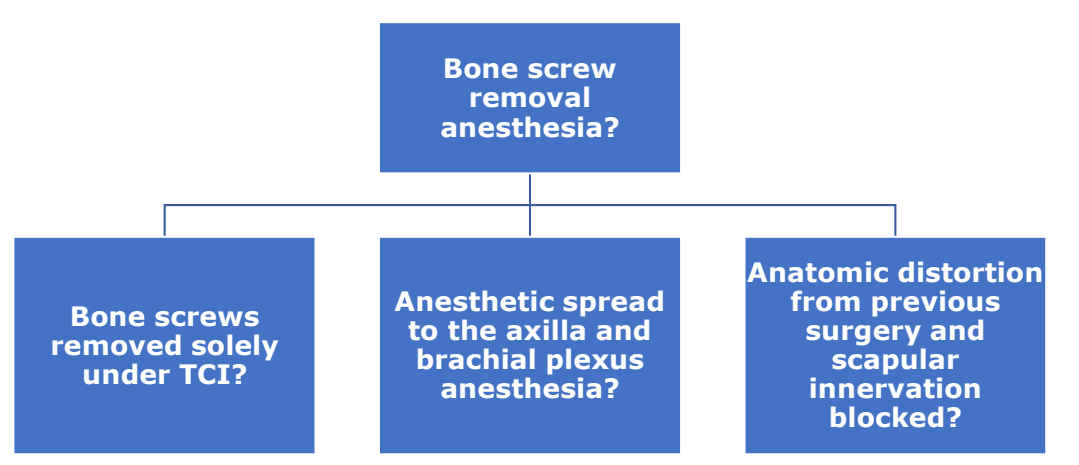

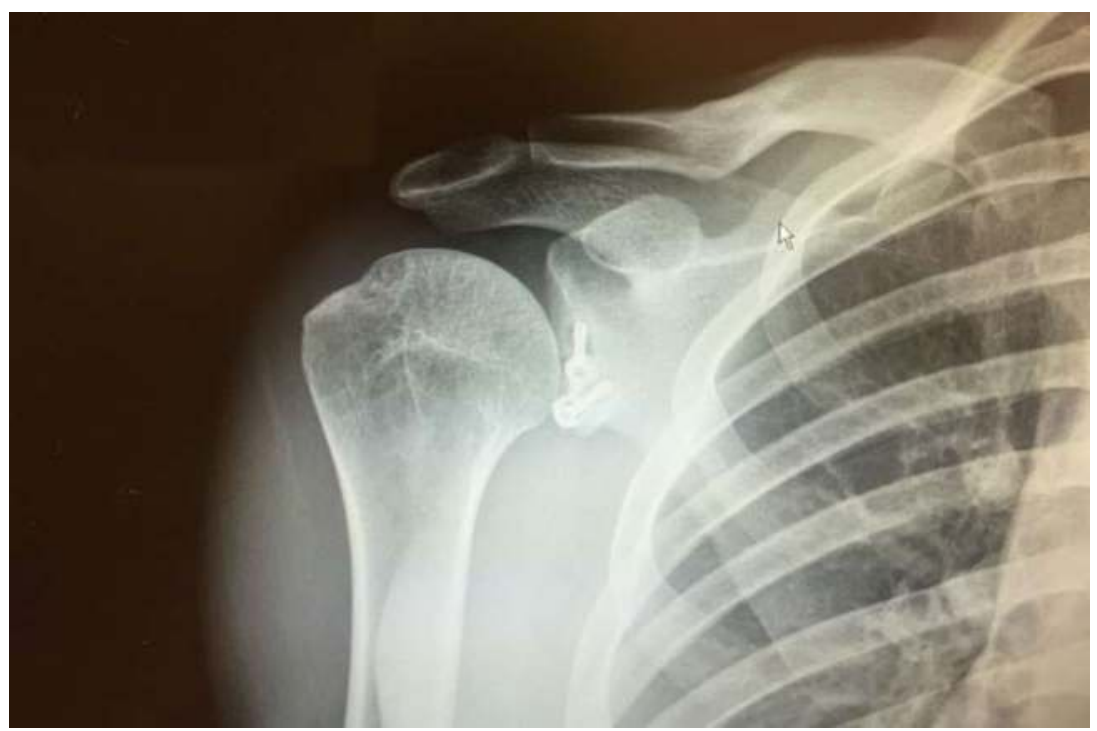

Preoperative shoulder $X$-ray showing the 2 glenoid bone screws which were removed.

\section{Conclusion}

- PECS II block is being increasingly used in surgeries other than breast surgery ${ }^{(2-4)}$.

- Actually, Schuitmaker et al, in 2017, already described PECS II as an useful analgesic adjuvant for shoulder girdle surgery (clavicular surgery) but all patients had surgery under general anesthesia combined with PECS II block (5).

- If combined with a superficial cervical plexus block, PECS II can be an alternative to interscalene brachial plexus block in selected shoulder girdle procedures with an anterior surgical approach, rendering upper extremity motor function intact.

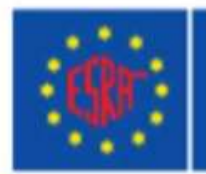

\section{State of the AT Salety Standards in $\mathrm{RA}$ THE EUROPEAN SOCIETY OF REGIONAL ANAESTHESIA \& PAIN THERAPY}

